\title{
Complex abdominal wall repair using a combination of porcine dermal matrix and omentum flap in patient with digestive tract fistula: report of a case and review of the literature
}

\author{
Michele Bartoli; Gian Luca Baiocchi, Andrea Celotti, Nazario Portolani, Stefano Maria Giulini \\ Department of Clinical and Experimental Sciences, Surgical Clinic, Brescia University, Brescia, Italy
}

Received: November 16, 2015

DOI: $10.5430 /$ crcp.v3n3p42
Accepted: January 5, $2016 \quad$ Online Published: June 6, 2016

URL: http://dx.doi.org/10.5430/crcp.v3n3p42

\begin{abstract}
Purpose: The purpose of this article is to propose an effective approach for giant abdominal wall defects repair in a contaminated field, using a combination of porcine dermal collagen graft (Permacol) and omental interpositional flap.

Case: We report a case of a 41-year-old woman submitted to emergency laparotomy, splenectomy and hepatic haemostasis for massive hemoperitoneum. She developed enteric fistula, cutaneous, muscolar and fascial necrosis leading to evisceration. At the fourth intervention we finally reconstructed abdominal wall defect using a combination of Parmacol and omental flap.

Conclusion: The reconstruction of large, full-thickness, eventually contaminated abdominal wall defects is often a challenging undertaking. Similar difficulties are usually encountered with early abdominal wall closure after damage-control surgery and/or open-abdomen management. In these situations the use of synthetic mesh is contrindicated; adsorbable mesh can be used as temporary solution and some techniques of autologous tissue repair have been suggested. Therefore no ideal operative repair technique or prosthetic material for reconstruction of the fascial defect is currently available in the literature. Recently, the development of biologic meshes has shown successful rates in the management of these parietal wall defects. Also in this patient, porcine dermal collagen mesh combined with omental flap allowed us to reconstruct large abdominal wall defect.
\end{abstract}

Key Words: Abdominal wall defects, Biological mesh, Permacol, Omental flap

\section{INTRODUCTION}

The reconstruction of large, full-thickness, eventually contaminated abdominal wall defects is often a challenging undertaking. Such hernia defects include those associated with exposure to enteric contents owing to ostomy creation and take-down, fistula, incarcerated or strangulated hernias, those created after the excision of infected prosthetic mesh, and those associated with acute tissue loss for severe trauma.
Similar challenges are usually encountered with early abdominal wall closure after damage-control surgery and/or open-abdomen management.

In these situations, no ideal operative repair technique or prosthetic material for reconstruction of the fascial defect is currently available. The use of synthetic mesh is largely (but non unanimously) agreed to be contraindicated owing to an high rate of perioperative complications, including wound

\footnotetext{
${ }^{*}$ Correspondence: Michele Bartoli, MD; Email: michelebartoli83@gmail.com; Address: Department of Clinical and Experimental Sciences, Brescia University III Chirurgia, P.le Spedali Civili 1, 25123, Brescia, Italy.
} 
infection, fistula formation, adherence and erosion of the viscera, ${ }^{[1-4]}$ especially when, in absence of peritoneum or omentum, the prosthetic device should be placed in direct contact with the bowel. ${ }^{[5,6]}$ Adsorbable mesh can be used in these situations; however, this solution is temporary and predisposes the patient to multiple operations and a staged abdominal wall reconstruction to achieve an acceptable functional result (sometimes, the very high operative risk precludes a two-stage surgical procedure ${ }^{[7]}$ ). A number of techniques such as component separation, ${ }^{[8]}$ musculocutaneous ${ }^{[9,10]}$ or pedicled omentum ${ }^{[11-13]}$ flaps have been suggested as a good alternative for autologous tissue repair, but the size of the defect often limit such possibilities, and the potential risk for donor site morbidity should be taken into account. ${ }^{[14]}$

Recently, the development of biologic meshes has shown successful rates in the management of these parietal wall defects. Such meshes allow to achieve a tension-free repair in a single-stage operation in the setting of contaminated wounds and in case of skin deficiency.

The purpose of this article is to propose an effective approach for giant abdominal wall defects repair in a contaminated field, using a combination of porcine dermal collagen graft (Permacol $^{T M}$, Surgical Implant, Covidian, Minneapolis) and omental inter-positional flap.

\section{CASE REPORT}

A 41-year-old woman was found in the street unconscious (GCS 4+2+1) and was submitted to oral intubation and successful cardiopulmonary resuscitation. At Emergency Room admission the patient was haemodynamically stable. Ultrasound showed the presence of haemoperitoneum, confirmed by CT scan, which found splenic (actively bleeding) and hepatic tears and multiple rib fractures. The patient was taken to the operating room. At this time no previous medical history was recordable; abdominal wall inspection revealed only a midline and a large suprapubic incisions. Emergency bilateral subcostal laparotomy was carried out, massive haemoperitoneum was confirmed (at least 2,000 ml blood was drawn out), splenectomy and hepatic hemostasis with surgical glue were performed.

Following the arrival of relatives to the hospital, the following important features were recorded: the patient was a Jehovah's Witness, had many risks factors including obesity overweight (BMI 28), hypertension, diabetes, type II bipolar disorder and hypokalemia arising from previous bariatric surgical procedures (firstly, biliopancreatic diversion, and secondly surgical revision for stretching common intestinal loop), and had undergone also abdominoplasty by the suprapubic incision.

Published by Sciedu Press
In $3^{\text {rd }}$ post-operative day (pod) the surgical wound presented cutaneous necrosis, followed by purulent secretion, leading to a first re-intervention in $8^{\text {th }}$ pod. Cutaneous and fascial necrosis was found; surgical toilette and necrosectomy were performed and vacuum-assisted (VAC Instill ${ }^{\circledR}$ Therapy Unit, $\mathrm{KCl}$ Medical, Acelity Company, Milano) closure system was applied. Six days after the second intervention the patient was further taken to operation room for evisceration and enteric fistula (see Figures 1-2). Intra abdominal adhesions were lysed. Enteric fistula was located on the alimentary tract $10 \mathrm{~cm}$ far from the anastomosis with biliopancreatic tract. The eviscerated bowel was completely covered by fibrin and hurt, so ileal resection of the eviscerated bowel and jejunal resection of alimentary tract with enteric fistula (together about $130 \mathrm{~cm}$ ) were performed. Intestinal continuity was restored with a total of 3 entero-entero anastomosis. The avital skin, subcutis and a part of abdominal wall involved by necrosis were removed. Full debridement resulted in abdominal wall defect of at least $20 \mathrm{~cm} \times 14 \mathrm{~cm}$. The resulting defect was placed in the upper abdominal wall extending from the right to the left anterior axillary line and from the xiphisternum to the umbilicus. Primary fascial clousure wasn't possible. The greater omentum was laid on bowel for protection. Above it a large dual mesh (Gore-Tex ${ }^{\circledR}$, ePTFE prosthesis, W.L.Gore and Associates, Flagstaff, Arizona) was placed to close the lack of the abdominal wall by suturing it to the remnant rim of abdominal muscles with Vicryl 2 interrupted sutures. A dermal substitute (Integra, IntegraTM Bilayer Matrix Wound dressing, Integra LifeSciences Corporation, New Jersey) was placed to cover the mesh. In 1st pod, VAC system was applied again by the plastic surgeon, but 3 days later the patient developed another enteric fistula and underwent surgery for the fourth time. After removing the contaminated dual mesh, dehiscence of the ileo-jejunal anastomosis was evident. Every kind of ostomy wasn't possible for the lack of abdominal wall. So, the anastomosis was resected and redo anastomosis was performed and reinforced by a seromuscular defunctionalizated jejunal flap. The omentum was mobilized from the transverse colon and the greater curvature of stomach and pedicled on the left gastroepiploic vessels. At this time a porcine dermal collagen implant (Permacol) was used to achieve wound's closure. A single Permacol piece was set into abdominal cavity strictly above the bowel and fixed to overlying anterior abdominal wall using polypropylene interrupted sutures. The exit point of the omental flap was a little slit located on the left subcostal site (see Figure 3).

The greater omentum was laid on the mesh, sutured to the abdominal wall using interrupted sutures and overlaid by fat gauze. After 22 days the wound was covered by granulation tissue so plastic surgeon covered skin defect with free thigh 
skin graft.

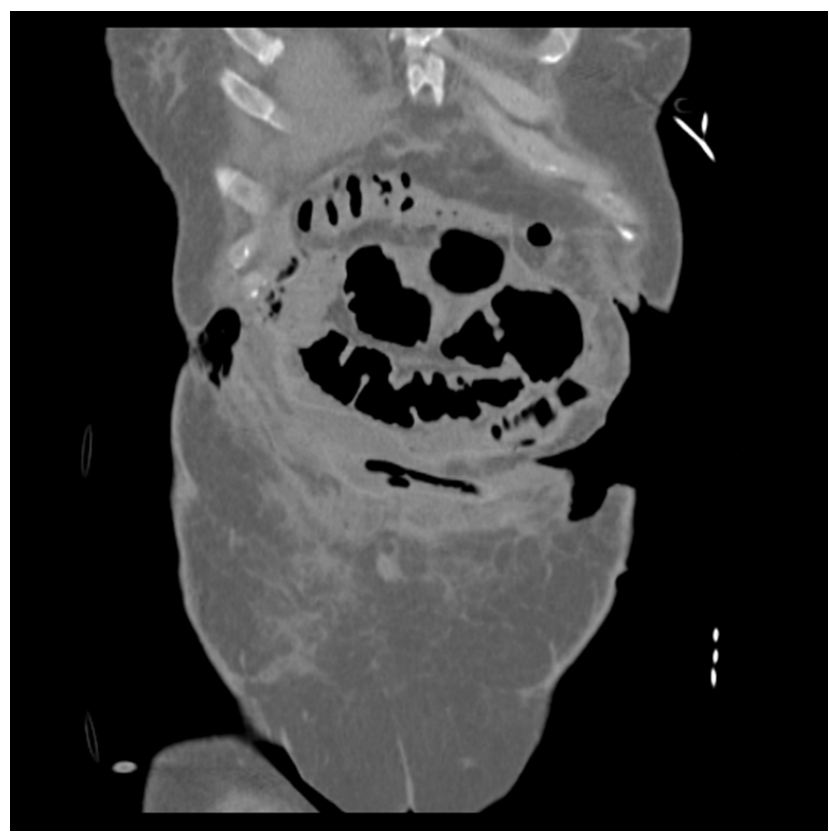

Figure 1. Frontal CT scan before the third intervention A large parietal defect leading to evisceration can be seen. The absence of muscolar, subcutaneous and cutaneous plane is more evident on the left side.

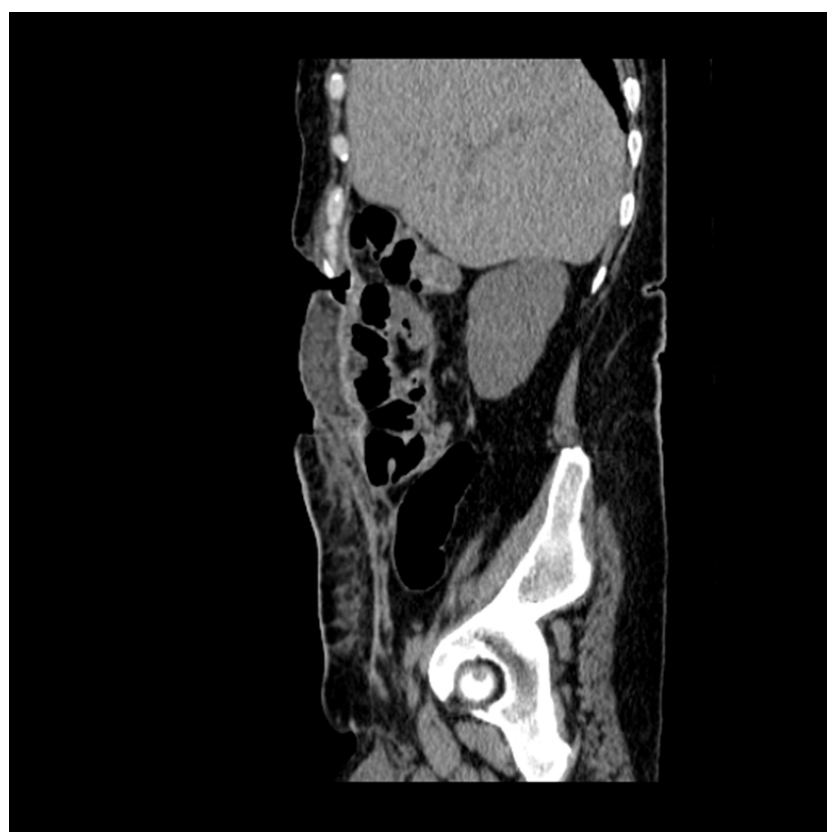

Figure 2. Sagittal CT scan before the third intervention

A small seroma spontaneously drained and self-limited after 5 month. At 10-month follow up the abdominal reconstruction is intact, there aren't signs of herniation, infection or fistula formation and the patient is able to perform normal daily activities.

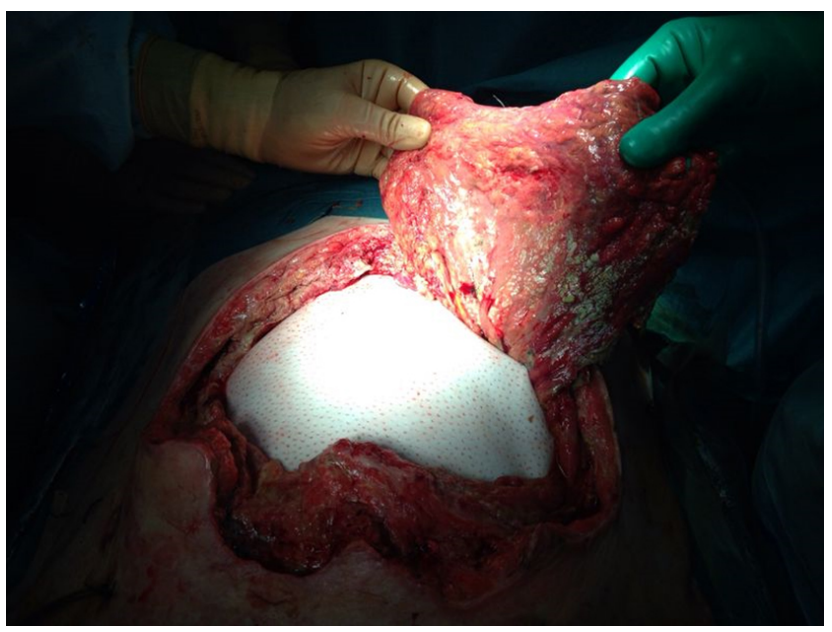

Figure 3. This picture taken in operating room shows the lost of substance of the abdominal wall at the fourth intervention

Permacol is just placed on bowel within peritoneal cavity and fixed to the overlying anterior abdominal wall. Omental flap exteriorized from the left subcostal site is going to be laid on the mesh and sutured to the abdominal wall using interrupted sutures.

\section{Discussion}

Abdominal wall reconstruction in case of digestive tract fistula is a complex problem. Multiple techniques are available, including use of synthetic materials, free flaps and grafts. In literature there aren't randomized trial or guidelines about this issue, but only case series or some retrospective studies with small sample. Thus we have to use our best judgment and the available data to make treatment choices. ${ }^{[15]}$ The recently available biologic meshes, which can theoretically be employed in contaminated wounds, may significantly improve the results in such cases.

Lopez Cano et al. ${ }^{[16]}$ has recently proposed a new definition of acute postoperative open abdominal wall (POAW). It is defined as the disjunction of all the abdominal wall's layers (cutaneous, muscular and peritoneal layers) that occurs after surgery. It can be intentional or unintentional depending on surgical-related actions. Intentional acute POAW or "open abdomen" ${ }^{[17]}$ consists in the surgeon's choice not to close the abdominal cavity and leave it open. Unintentional acute POAW (or "burst abdomen", "evisceration", "wound dehiscence", "wound disruption") is a common postoperative complication in abdominal surgery that consists in the partial or total opening of the laparotomy. ${ }^{[18]}$ Wound opening may be complete involving muscular and cutaneous layers or incomplete when the skin is not involved ("ventral hernia"). In unintentional acute POAW there are some different subgroups. Each group has different management regarding definitive early or delayed closure. The presence of intra 
abdominal abscesses, the presence or absence of enterocutaneous or enteroatmosferic fistulas ${ }^{[19-21]}$ and the possibility of early closure without tension of the laparotomy are some of the possible scenarios in which the surgeon has to choose the right treatment strategy. Our patient should be included in the subgroup of patients with complete wound failure and enterocutaneous fistula. For this kind of patients there are no guidelines. ${ }^{[16]}$

Reinforced repair is defined as use of mesh. The anatomic position of the mesh is defined as subcutaneous on the top of the anterior rectus fascia ("onlay"), between the rectus muscle and the posterior rectus fascia ("preperitoneal underlay" or Rives-Stoppa technique), behind the posterior rectus fascia ("intraperitoneal underlay") or within the defect and sutured directly to the fascial edges ("interpositional" or "inlay"). Mesh's use has significantly decreased recurrence rates of hernia repair. Synthetic materials, such as Polypropylene or ePTFE, are commonly employed but they can cause complications including wound infection, intra abdominal adherences, entero-cutaneous fistula and lack of tissue in-growth into the mesh. ${ }^{[22,23]}$

After synthetic mesh repair, prosthesis removal is often mandatory when infection develops. In a meta-analysis of incisional hernia repair with synthetic prosthesis, infection requiring mesh removal occurred in $10.1 \%$. $^{\text {[24] }}$

For the above mentioned reasons, the use of autologous tissue flap and graft has been advocated. ${ }^{[25]}$ However, a meta-analysis of the component separation technique ${ }^{[8]}$ for ventral hernia repair showed an $18.9 \%$ infection rate, contributing to an overall complication rate of $23.8 \%$, including flap necrosis and donor-site related complications, thus even higher than synthetic mesh repair complication rate. ${ }^{[25,26]}$ Collagen-based biological materials have been developed to overcome these problems. The concept behind biological implants is to provide a collagen and other extracellular matrix scaffold in which the host fibroblasts can create angiogenesis and deposit new collagen. Currently available bio synthetic mesh include human cadaveric dermis (AlloDerm ${ }^{\circledR}$ ), porcine dermal (Permacol ${ }^{\circledR}$ and Strattice ${ }^{\circledR}$ ) and submucosal (Surgisis ${ }^{\circledR}$ ) sources. In a recent literature review by Slater, biologic prosthesis for ventral hernia repair perform similarly to other surgical options. However, they were associated with higher salvage rate in cases of infection. Infection is the most common postoperative complication even with biologic grafts (overall rate of $15.9 \%$ ), but the majority of infections are superficial, and the biologic mesh could almost always be savaged (grafts are removed in only $4.9 \%$ of infected cases). ${ }^{[27]}$

In a literature review by Smart et al., ${ }^{[28]}$ Permacol ${ }^{\circledR}$ surgical implant has the lowest failure rate and the longest time to failure, particularly in contaminated fields. These results are concordant with findings from high-quality animal studies. Permacol ${ }^{\circledR}$ surgical implant is a cross-linked porcinederived acellular dermal sheet predominantly composed of Type I collagen. It is resistant to the collagenase enzymes responsible for the breakdown and resorption of implanted collagen ${ }^{[29,30]}$ and is also able to support host cell infiltration and revascularization, and within a few months it becomes an integral part of body. Permacol ${ }^{\circledR}$ does not facilitate the formation of a biofilm in the presence of infection and thus is ideal for use in operations with a high risk of infection. ${ }^{[31]}$

Permacol $^{\circledR}$, as all type of biological mesh, can be left to direct contact with bowel and adipose tissue but needs to be covered and can't stay exposed to air. Cross linked biologic prosthetics are more resistant and have higher bursting strengths, whereas noncross-linked biologics support host cellular ingrowth. Cross linked mesh become encapsulated as opposed to incorporated into host tissues. Totally cross-linked mesh will not incorporate into host tissues at all, whereas partly cross-linked prosthesis will incorporate to some degree. A major issue surrounding Permacol and all the other biologic grafts is their high price. According to the type of mesh, the price varies between $\$ 2.845$ and $\$ 5.311$ for $150 \mathrm{~cm}^{2}$ prosthesis. This kind of prosthesis is not largely used in Europe because of their high costs. More convincing evidence of their performance and accurate indication is awaited. The Food And Drug Administration reported adverse events with the use of these meshes that warrant caution and judicious decision making. Because of the theorized structural remodeling of biologic graft, the long term integrity of abdominal wall after reconstruction remains unknown. So we need studies with longer follow-ups to really determinate the durability of biologic meshes given their biodegradable nature.

In the presented case there was no sufficient skin or tissue to cover the mesh; thus, pedicled omentum flap was used. In many cases, owing to the large size of defect, the use of abdominal wall flaps to cover prosthetic mesh is not possible, while a pedicled omentum flap is easy to prepare, and it can reach defects over all quadrants of the abdominal wall. Lower abdominal wall defects may be managed with flaps from thigh such as tensor fascia lata flap, ${ }^{[32]}$ instead the upper abdominal wall is more challenging although extended tensor fascia lata or latissimus dorsi flaps or extended deep inferior epigastric flap have all been described. ${ }^{[33,34]}$ The omentum consists of abundant blood vessels, fat, and lymphatic tissue and is known for its unique immunologic and angiogenic proprieties. ${ }^{[35]}$ Therefore it can be used in infected or contaminated situations and an additional free skin 
graft could easily placed over it. The utility of the omentum as a flap in reconstructive surgery is well documented, but also this technique presents donor-site complications such as abdominal wall infection, hernia, delayed splenic rupture, gastrointestinal hemorrhage, and, later, small bowel obstruction, early satiety and transient gastric outlet obstruction. In a retrospective series, C. Scott Hultman et al. ${ }^{[36]}$ found a donor-site complication rate of $18.5 \%$.

\section{Conclusion}

In conclusion, in the management of large, infected abdominal wall defect, the use of Permacol ${ }^{\circledR}$ combined with omentum flap offer a safe and effective alternative to traditional hernia repairs.
Permacol ${ }^{\circledR}$ could be placed in contaminated surgical fields and the omentum flap is easy to prepare and reduces donor site defects and morbidities resulting from musculocutaneous flap. This technique offers the opportunity for a single-staged reconstruction in large full thickness abdominal wall defect. It is also a surgical option when neither synthetic prosthetic mesh nor musculocutaneous flap can be used to achieve closure. However the experience is too small to draw definitive conclusions about the suitability of the technique. So it is highly mandatory a larger and well designed study with long follow-up to corroborate the findings presented in this case report.

\section{CONFlicts of INTEREST Disclosure}

The authors declare no conflicts of interest.

\section{REFERENCES}

[1] Brown GL, Richardson JD, Malangoni MA, et al. Comparison of prosthetic materials for abdominal wall reconstruction in the presence of contamination and infection. Ann Surg. 1985; 201: 705-11. PMid: 3159353. http://dx.doi.org/10.1097/00000658-198 506000-00006

[2] Cobb WS, Harris JB, Lokey JS, et al. Incisional herniorrhaphy with intraperitoneal composite mesh: a report of 95 cases. Am Surg. 2003; 69: 784-7. PMid: 14509327.

[3] Candage R, Jones K, Luchette FA, et al. Use of human acellular dermal matrix for hernia repair: Friend or foe? Surgery. 2008; 144(4): 703-11. PMid: 18847657. http://dx.doi.org/10.1016/j.sur g. 2008.06.018

[4] Patton JH, Berry S, Kurt AK, et al. Use of human acellular dermal matrix in complex and contaminated abdominal wall reconstructions. Am J Surg. 2007; 193: 360-63. PMid: 17320535 http://dx.doi.org/10.1016/j.amjsurg. 2006.09.021

[5] Fernandez RL, Martinez CS, Ortega PD, et al. Colocutaneous fistula due to polypropylene mesh. Hernia. 2001; 5(2): 107-9. PMid: 11505647. http://dx.doi.org/10.1007/s100290100003

[6] Campanelli G, Nicolosi FM, Pettinari D, et al. Prosthetic repair, intestinal resection, and potentially contaminated areas: safe and feasible? Hernia. 2004; 8(3): 190-2.

[7] Catena F, Ansaloni L, Gazzotti F, et al. Use of porcine dermal collagen graft (Permacol) for hernia repair in contaminated fields. Hernia 2007; 11: 57-60. PMid: 17119853. http://dx.doi.org/10.10 07/s10029-006-0171-6

[8] Ramirez OM, Ruas E, Dellon AL. "Component separation" method for closure of abdominal-wall defects: an anatomie and clinical study. Plast Reconstr Surg. 1990; 86(3): 519-26. PMid: 17119853 http://dx.doi.org/10.1097/00006534-199009000-00023

[9] Disa JJ, Goldberg NH, Carlton JM, et al. Restoring abdominal wall integrity in contaminated tissue-deficient wounds using autologous fascia grafts. Plast Reconstr Surg. 1998; 101: 979-86. PMid: 9514330. http://dx.doi .org/10.1097/00006534-199804040-00014

[10] Yan G, Rui T, Gong DQ, et al. Reconstruction of the abdominal wall by using a combination of the human acellular dermal matrix implant and an interpositional omentum flap after extensive tumor resection in patients with abdominal wall neoplasm:
A preliminary result. World J Gastroenterol. 2008; 14(5): 752-57. http://dx.doi.org/10.3748/wjg.14.752

[11] El-Muttardi N, Lancaster K, Ng R, et al. The sandwich omental flap for abdominal wall defect reconstruction. Br J Plast Surg. 2005; 58 : 841-44. PMid: 16086992. http://dx.doi.org/10.1016/j.bjp s. 2004.12 .031

[12] Wong CH, Tan BK, Koong HN, et al. Use of the omentum flap as additional soft tissue cover for abdominal wall defects reconstructed with Gore-Tex. Plast Reconstruct Surg. 2005; 116: 1715-20.

[13] Bleichrodt RP, Malyar AW, de Vries Reilingh TS, et al. The omentumpolypropylene sandwich technique: an attractive method to repair large abdominal wall defects in the presence of contamination or infection. Hernia. 2007; 11: 71-74. PMid: 17160499 http://dx.doi.org/10.1007/s10029-006-0174-3

[14] Jernigan TW, Fabian TC, Croce MA, et al. Staged management of giant abdominal wall defects: acute and long-term results. Ann Surg. 2003; 238: 349-55. http://dx.doi.org/10.1097/01.sla.00 00086544.42647 .84

[15] Johnson EK, Tushoski PL. Abdominal wall reconstruction in patients with digestive tract fistulas. Clin Colon Rectal Surg. 2010; 23: 195-208. PMid: 21886470. http://dx.doi.org/10.1055/s-0 030-1262988

[16] Lopez CM, Pereira JA. "Acute postoperative open abdominal wall": Nosological concept and treatment implications. WJGS. 2013; 27(5): 314-20.

[17] Friese RS. The open abdomen: definitions, management principles, and nutrition support considerations. Nutr Clin Pract. 2012; 27: 492 8. PMid: 22714062. http://dx.doi.org/10.1177/088453361 2446197

[18] Carlson MA. Acute wound failure. Surg Clin North Am. 1997; 77: 607-36. http://dx.doi.org/10.1016/S0039-6109(05) 7 0571-5

[19] Schessel ES, Ger R, Gunaseelan A, et al. The management of the postoperative disrupted abdominal wall. Am J Surg. 2002; 184: 263-68. http: //dx.doi.org/10.1016/S0002-9610(02)00935-2

[20] van Ramshorst GH, Nieuwenhuizen J, et al. Abdominal wound dehiscence in adults: development and validation of a risk model. Warld $\mathbf{J}$ Surg. 2010; 34: 20-7. 
[21] Papaziogas B, Koutelidakis I, Tsaousis P, et al. Use of mesh for management of post-operative evisceration. Surg Chron. 2012; 17: 103-7.

[22] Geisler DJ, Reilly JC, Vaughan SG, et al. Safety and outcome of use of nonabsorbable mesh for repair of fascial defects in the presence of open bowel. Dis Colon Rectum. 2003; 46: 1118-23. PMid: 12907910. http://dx.doi.org/10.1007/s10350-004-7290-x

[23] Gentile P, Colicchia GM, Nicoli F, et al. Complex abdominal wall repair using a porcine dermal matrix. Surg Innov. 2013; 20(6): 1-4. PMid: 22006210. http://dx.doi.org/10.1177/15533506114 21022

[24] Forbes SS, Eskicioglu C, McLeod RS, et al. Meta-analysis of randomized controlled trials comparing open and laparoscopic ventral and incisional hernia repair with mesh. Br J Surg. 2009; 96: 851-58. PMid: 19591158. http://dx.doi.org/10.1002/bjs.6668

[25] Rohrich RJ, Lowe JB, Hackney FL, et al. An algorithm for abdominal wall reconstruction. Plast Reconstr Surg. 2000; 105: 202-16. PMid: 10626993. http://dx.doi.org/10.1097/00006534-2 00001000-00036

[26] de Vries Reilingh TS, Bodegom ME, van Goor H, et al. Autologous tissue repair of large abdominal wall defects. Br J Surg. 2007; 94: 791803. PMid: 17571292. http://dx.doi.org/10.1002/bjs. 5817

[27] Slater NJ, Marion van der Kolk, Hendriks T, et al. Biologic grafts for ventral hernia repair: a systematic review. Am J Surg. 2013; 205 : 220-30. PMid: 23200988. http://dx.doi.org/10.1016/j.amj surg. 2012.05.028

[28] Smart NJ, Marshall M, Daniels IR, et al. Biological meshes: a review of their use in abdominal wall hernia repairs. Surgeon. 2012; 10(3): 159-71. PMid: 22436406. http://dx.doi.org/10.1016/j . sur ge. 2012.02 .006
[29] Harper C. Permacol: clinical experience with a new biomaterial. Hosp Med. 2001; 62(2): 90-5. PMid: 11236624. http://dx.doi .org/10.12968/hosp.2001.62.2.2379

[30] Chand B, Indeck M, Needleman B, et al. A retrospective study evaluating the use of Permacol surgical implant in incisional and ventral hernia repair. Int J Surg. 2014; 1-8. http://dx. doi.org/10.10 $16 / j$.ijsu. 2014.01.025

[31] Moore RD, Miklos JR, Kohli N. Rectovaginal fistula repair using a porcine dermal graft. Obstet Gynecol. 2004; 104(5): 1165-67. PMid: 15516438. http://dx.doi.org/10.1097/01.A0G.0000 128116.52051 .10

[32] Dibbell Jr DG, Mixter RC, Dibbell Sr DG, et al. Abdominal wall reconstruction (the "mutton chop"flap). Plast Reconstruct Surg. 1991; 87: 60-5.

[33] Watson JS. Reconstruction of the anterior abdominal wall above the umbelicus using a tensor fascia latae myocutaneous island flap. Br J Plast Surg. 1983; 36: 334-6. http://dx.doi .org/10.1016/S00 07-1226 (83) 90055-3

[34] Houston GC, DrewGS, Vazquez B, et al. The extended latissimus dorsi flap in repair of anterior abdominal wall defects. Plast Reconstruct Surg. 1988; 81: 917-24.

[35] Liebermann-Maffert D. The greater omentum. Anatomy, embryology, and surgical applications. Surg Clin North Am. 2000; 80: 275-93.

[36] Scott HC, Carlson GW, Losken A, et al. Utility of the omentum in the reconstruction of complex extraperitoneal wounds and defects: donor-site complications in 135 patients from 1975 to 2000. Ann Surg. 2002; 235(6): 782-95. PMid: 12035034. http://dx.doi.o $\mathrm{rg} / 10.1097 / 00000658-200206000-00005$ 